\title{
Design of a Planar MIMO Antenna for LTE-Advanced
}

\author{
A.A. Asaker \\ Egyptian Atomic Energy \\ Authority, \\ Cairo, Egypt.
}

\author{
R.S. Ghoname \\ Faculty of Engineering Girls' \\ Campus \\ King Abdul-Aziz University, \\ Jeddah, Saudi Arabia (1) \\ Electronics Research Institute, \\ Cairo, Egypt (2)
}

\author{
A.A. Zekry \\ Professor, Department of \\ Electronics and Communication \\ Engineering, \\ Faculty of engineering Ain \\ Shams University, Cairo, Egypt
}

\begin{abstract}
This paper presents the design of a wideband microstrip patch antenna for LTE-A. The bandwidth of the conventional patch is enlarged by using etched slots at the antenna patch. The designed antenna has been fabricated by using thin film and photolithographic technique and has been measured by using the Vector Network Analyzer. The simulated and measured results were found to have good match with each other. Then, by using the designed single element antenna, a four-element MIMO antenna system has been built employing orthogonal polarization diversity. Isolation between the microstrip elements is increased by placing metal structure between antenna elements. For more isolation between antenna elements, Slotted Ground Plane SGP is utilized. It is found, by using commercial software CST Microwave Studio and measurement, that the designed planar MIMO antenna system has sufficiently high return loss and low mutual coupling at the required bandwidth of $70 \mathrm{MHz}$. It is found also that the developed antenna system meets the requirements for LTEAdvanced $(2500-2570 \mathrm{MHz})$ band "CA-B7" as of today's standard based on 36.101 Table 5.5-1 (March 2012) .
\end{abstract}

\section{General Terms}

MIMO antennas, Frequency characteristics, Mutual coupling, Correlation coefficient.

\section{Keywords}

MIMO systems, SISO systems, Polarization diversity, LTE-A, Mutual coupling, Slotted ground plane "SGP", Isolating metal structure.

\section{INTRODUCTION}

In recent wireless communication systems, MIMO technology plays a key role for improving the data rate, transmission speed and channel capacity. To take full advantage of the MIMO antenna technology; it is desirable to implement as many antennas as possible both at the base station and at the terminals. From the antenna design perspective, utilizing multiple antennas at the base station is not difficult since enough space is available, whereas the number of antenna elements is limited in terminal devices due to their limited size. Thus, antennas implementation at the terminals becomes the primary factor limiting the theoretical MIMO performance in the wireless communication systems. In comparison to a single antenna for a SISO system, multiple antennas which are employed for MIMO system must have compact size, low profile and meet some additional requirements such as good isolation and lower correlation.

In this project, Microstrip array antennas are used, Because of its attractive features of low profile, light weight, easy fabrication, and conformability to mounting hosts which makes it suited for customer applications [3-6]. Unfortunately, a classical Microstrip patch antenna has a very narrow bandwidth which limits its use in commercial applications such as $3 \mathrm{G}$ and $4 \mathrm{G}$ wireless systems. However, if the antenna bandwidth could be widen, a wide-band Microstrip antenna would prove very useful in such that applications. For these reason studies to achieve compact and wide-band applications of microstrip antennas have greatly increased [7]. Researchers have devised several methods to increase the bandwidth of Microstrip antenna in addition to the common techniques of increasing the patch height, decreasing substrate permittivity. This includes using a multilayer structure consisting of several parasitic elements with slightly different sizes above the driven element (a stacked patch antenna) [8], a planer patch antenna surrounding by closely spaced parasitic patches (a coplaner parasitic sub array) [9] or by implementing internal structures such as slots [10], [13]. The stacked patch antenna increases the thickness of the antenna while the coplanar increases the lateral size of the antenna. In this design we used the embedded slots as the major method for improving the antenna bandwidth because it has its advantages such as it does not increase the lateral size of the microstrip antenna on the other hand it is easy in fabrication.

MIMO channel capacity theoretically increases linearly with the minimum number of antennas at transmit and receive sides, but Mutual coupling between antennas (i.e. the electromagnetic interactions between the elements) can cause loss of spectral efficiency and degrade performance of a MIMO system. Then the basic aim of MIMO antennas design in a compact wireless terminal is to minimize the Mutual coupling between closely placed antenna array elements. The mutual coupling mainly depends on the distance between the elements of an antenna array. By increasing the distance between the elements, the mutual coupling can be reduced. The distance between antenna elements in practice cannot be extended beyond a certain level which limits the use of spatial diversity to achieve the desired spectral efficiencies and transmission qualities. As an alternative solution to achieve compactness in MIMO systems, the use of pattern diversity $[18,19]$, multimode diversity [14], and polarization diversity [[20], [21] techniques in conjunction with space diversity. In this MIMO design, polarization diversity is mainly considered as the results from [20], and [21] which indicate that this technique improves the channel capacity with lesser spacing between the elements. For more isolation between antenna elements, two techniques have been employed. The first technique is to place a rectangular metal structure between the two microstrip antenna elements, and the second technique is to modify the ground plane by introducing a rectangular slot on the space between the elements.

\section{ANTENNA DESIGN}

The proposed antenna is printed on an FR4 substrate having dielectric constant of $\varepsilon r=4.4$, a tangent loss of 0.02 and a 
thickness of $1.6 \mathrm{~mm}$, and simulated in the frequency range from 2.4 to $2.7 \mathrm{GHz}$. In this design we considered the modified rectangular patch which is presented in reference [11], because of its compact size which is much smaller compared to the conventional rectangular microstrip antenna [2] and recent published modified rectangular shapes [15], [16], [17], [24]. By doing some dimensional modification and scaling on the initial antenna shape, the antenna is made to resonate at the intended frequency but its bandwidth is still too small for LTE-A. Such antenna geometry is depicted in Fig. 1 and its simulated reflection coefficient S11 is shown in Fig. 2. It is observed that the antenna has a resonance frequency at $2.522 \mathrm{GHz}$ with a bandwidth of $35 \mathrm{MHz}$, which is smaller than that required for LTE-Advanced, the dimensions of the patch are included in Table 1.

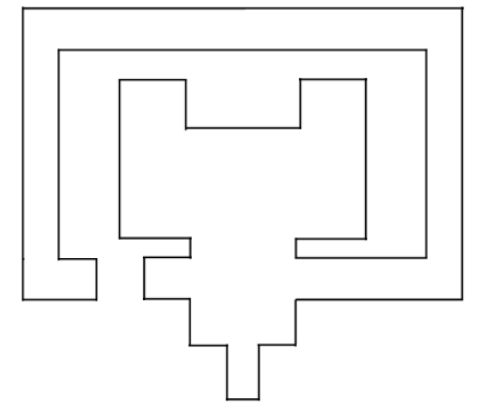

Fig. 1: Geometry of the initial proposed patch antenna

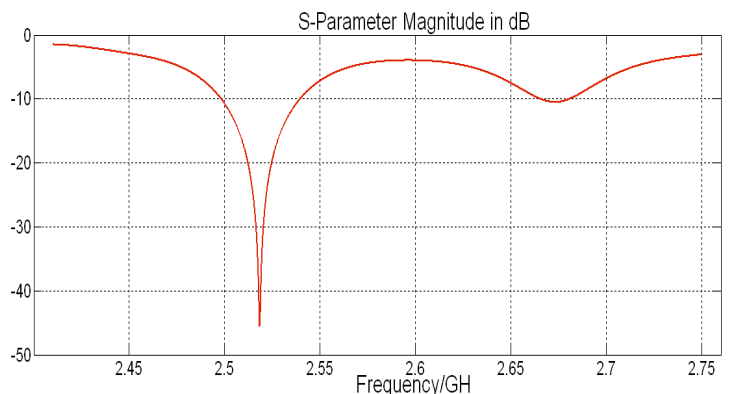

Fig. 2: Simulated result of return loss, S11 of the initial patch

In order to enlarge the bandwidth of the patch, slots are made in it. Fig. 3 shows the modified patch with two embedded horizontal slots while Fig. 4 depicts the simulated reflection coefficient indicating the bandwidth increase, but it is still smaller than targeted one. More over one observes that a new resonance mode has been introduced near to the fundamental mode but there is a band gap in between at which the return loss is higher than $-10 \mathrm{~dB}$. So, one has to introduce vertical slots to reach the required bandwidth. A total of four vertical slots are added to realize the required bandwidth. The final antenna deign is shown in Fig. 5 and its dimensions are illustrated in Table 1.

From the simulation results of the final patch shown in Fig.7, it is noted that the antenna effective electrical length is increased and hence the two resonances are shifted to the lower frequency, also it is noted that there is an improvement for return loss such as the magnitude of S11 decreases.

It is clear also from Fig. 7 that the designed antenna resonates at $2.53 \mathrm{GHz}$ with bandwidth of $100 \mathrm{MHz}$ from $2.48 \mathrm{GHz}$ up to $2.58 \mathrm{GHz}$.

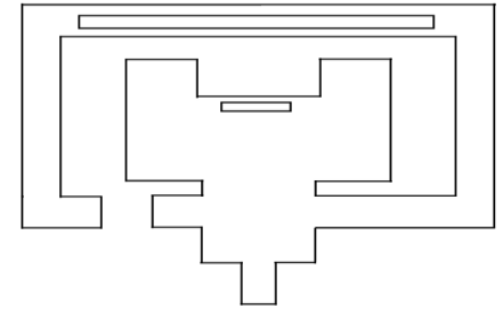

Fig. 3: Geometry of proposed patch antenna with horizontal slots

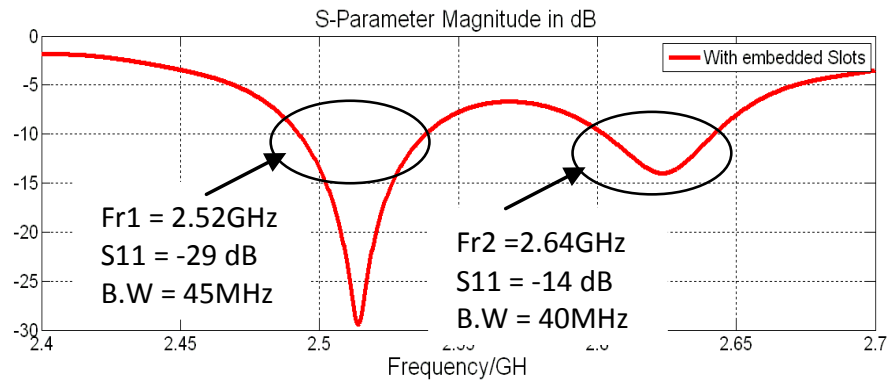

Fig.4: Simulated results of return loss, S11 for the patch with horizontal slots

By comparing the simulation results shown in Fig. 2 and Fig. 7 , it is observed that after introducing embedded slots on the patch, the bandwidth is enlarged such that the bandwidth of Rectangular Microstrip antenna with embedded slots equals 285\% of Rectangular Microstrip antenna without embedded slots. These slots support bandwidth enhancement by introducing new resonance modes excited near the fundamental mode having the same polarization planes and similar radiation characteristics. When the resonance frequency ratio is obtained to be so small then two or more adjacent modes are well excited simultaneously and consequently the bandwidth will be twice or more than that for the single resonance to cover the desired band of 2.5 to $2.57 \mathrm{GHz}$ frequency [10].

After designing the antenna, it is fabricated by photolithographic techniques on Fr4 PCB board and its photograph is shown in Fig. 6. Its return loss is measured using vector network analyzer and plotted in Fig. 7 together with the simulated return loss for sake of comparison. It is noted from Fig.7, that there is satisfactory agreement between simulation and measurement results of the single element antenna but there is about $30 \mathrm{MHz}$ shift between the measured and simulated data due to the effect of substrate parameter (dielectric constant and thickness),improper soldering of SMA connector or fabrication tolerance.

In Fig 8, the simulated results show that the VSWR is less than 2 within the required bandwidth. It is an acceptable value to ensure less power being reflected back to the source.

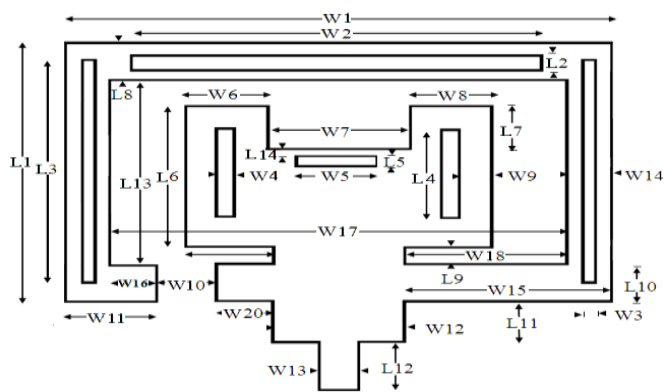

Fig. 5: Geometry of the final patch antenna. 


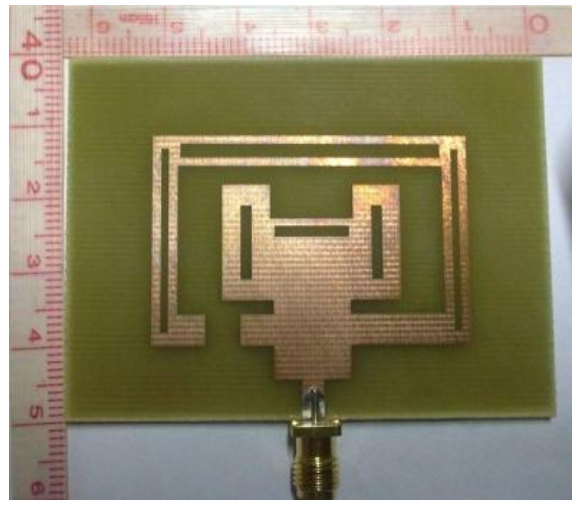

Fig.6: Fabricated Patch Antenna

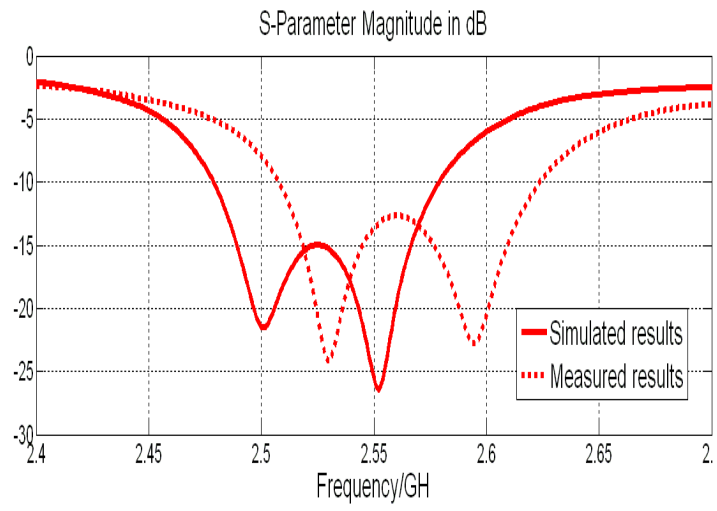

Fig.7: The return loss plot of measurement and simulation for the proposed antenna

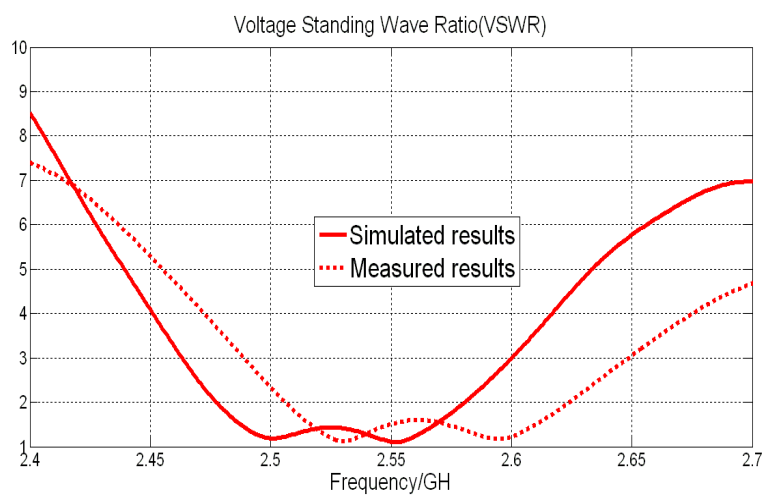

Fig.8: VSWR plot of measurement and simulation for the proposed antenna

An illustration is shown in Fig. 9 (a), where the principal planes of a microstrip antenna are plotted. The $X Y$ plane is the principal $\mathrm{E}$ plane, and the $\mathrm{XZ}$ plane is the principal $\mathrm{H}$ plane.

Fig. 9 (b), and (c) respectively, shows the simulated radiation pattern at $\Phi=0^{\circ}$ (E-Plane) and $\Phi=90^{\circ}$ (H-Plane) for the proposed antenna at the resonant frequency $\mathrm{Fr}=2.53 \mathrm{GHz}$. From the polar figure, the designed antenna produces directional pattern. It is noted that the main beam angle is about broadside angle with half-power beam width (HPBW) of $106.8^{\circ}$. Also it is noted that the back lobe radiation is sufficiently small. This low back lobe radiation is an added advantage for using this antenna in a cellular phone, since it reduces the amount of electromagnetic radiation which travels towards the users head.

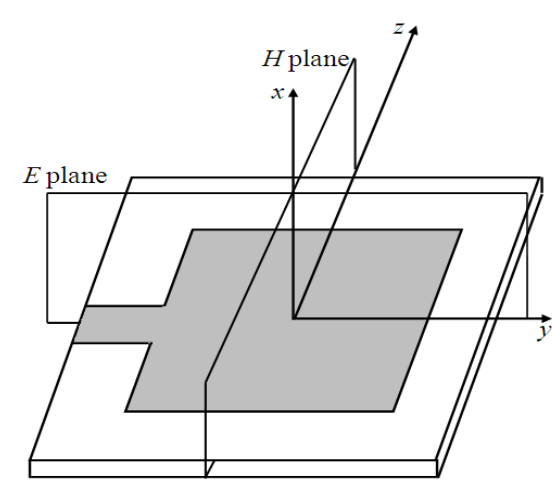

(a)

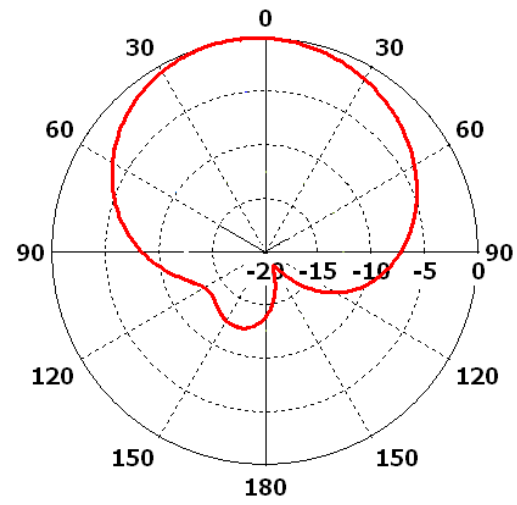

(b)

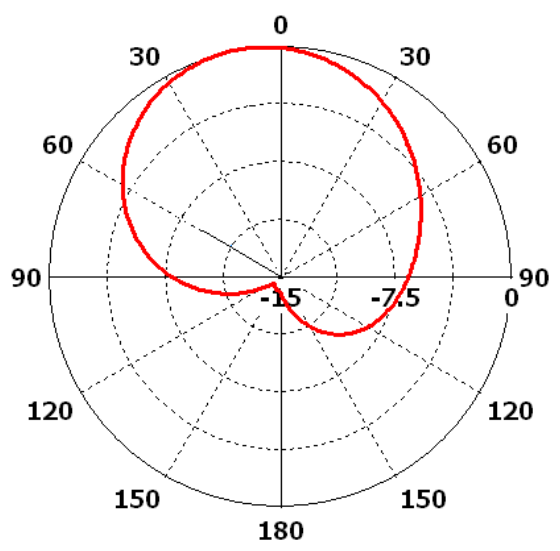

(c)

Fig. 9: Simulated Far-field Radiation Pattern at $2.53 \mathrm{GHz}$. (a)The principal-plane patterns of a microstrip antenna

(b) Radiation pattern For (XY) E-plane $\Phi=0$.

(c) Radiation pattern For (XZ) H-plane $\Phi=90$.

Table1: Dimensions and basic parameters of proposed patch antenna

\begin{tabular}{|c|c|c|c|}
\hline \multicolumn{2}{|c|}{ Length in mm } & \multicolumn{2}{c|}{ Width in mm } \\
\hline L1 & 28.2668 & W1 & 42.4534 \\
\hline L2 & 2 & W2 & 35 \\
\hline L3 & 25 & W3 & 1 \\
\hline
\end{tabular}




\begin{tabular}{|c|c|c|c|}
\hline L4 & 10 & W4 & 1.5 \\
\hline L5 & 1.5 & W5 & 10 \\
\hline L6 & 15.5 & W6 & 6.34 \\
\hline L7 & 4.64 & W7 & 11.2 \\
\hline L8 & 4 & W8 & 6.34 \\
\hline L9 & 1.95 & W9 & 2.42 \\
\hline L10 & 4 & W10 & 4.69 \\
\hline L11 & 4.52 & W11 & 7 \\
\hline L12 & 5 & W12 & 10.22 \\
\hline L13 & 20.13 & W13 & 2.89 \\
\hline L14 & 0.9 & W14 & 4 \\
\hline \multirow{3}{*}{$\begin{array}{c}\text { Center } \\
\text { Frequency Fr }\end{array}$} & \multirow[t]{3}{*}{$2.53 \mathrm{GHz}$} & W15 & 16.12 \\
\hline & & W16 & 3.67 \\
\hline & & W17 & 35.76 \\
\hline \multirow{3}{*}{$\begin{array}{l}\text { Bandwidth } \\
\text { (f2-f1) }\end{array}$} & \multirow[t]{3}{*}{$100 \mathrm{MHz}$} & W18 & 12.77 \\
\hline & & W19 & 6.83 \\
\hline & & W20 & 4.41 \\
\hline
\end{tabular}

metal structure between antenna elements. For more isolation Slotted Ground Plane "SGP" is utilized as shown in Fig.10. By increasing the metal structure width " $h$ " and ground slot width "g", the mutual coupling between antenna elements is improved while the return loss is affected. Certain value of "h" and "g" are chosen in which the transmission coefficient and reflection coefficient are the best. The metal structure width is $4 \mathrm{~mm}$, ground slot width $4 \mathrm{~mm}$ and the separation between the elements is $9 \mathrm{~mm}(\approx 0.075 \lambda \circ)$ which is the minimum separation between elements to be decoupled. Here polarization diversity is mainly considered as the results from [20], and [21] which indicate that this technique improves the channel capacity with lesser spacing between the elements.

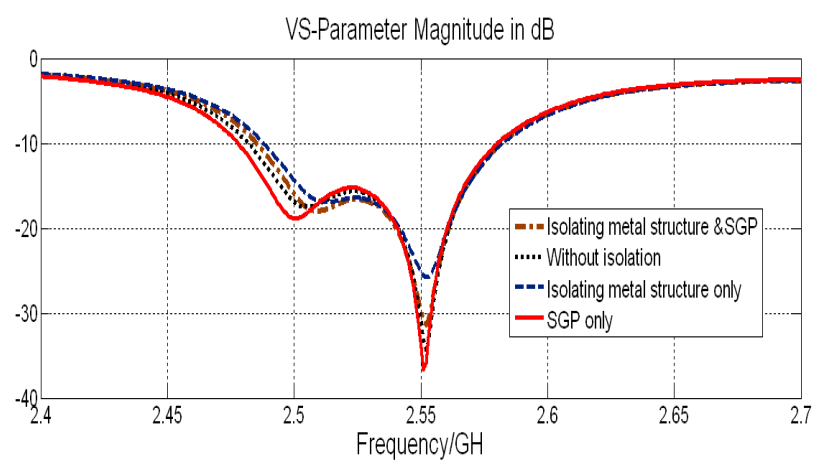

(a)

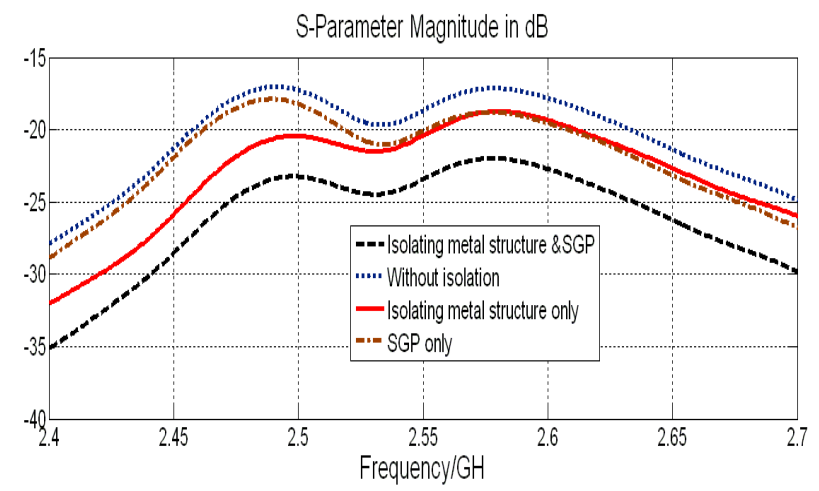

(b)

Fig.11: The simulation results of two space polarized antennas with $9 \mathrm{~mm}$ separation

(a) Reflection coefficient. (b) Transmission coefficient.

From the results presented in the Fig .11 (b), it is evident that after introducing $4 \mathrm{~mm}$ metal-strip between the two elements as well as slotted ground plane 'SGP' underlying the strip as shown in Fig.10, the mutual coupling is reduced from $-17 \mathrm{~dB}$ to $-22 \mathrm{~dB}$.

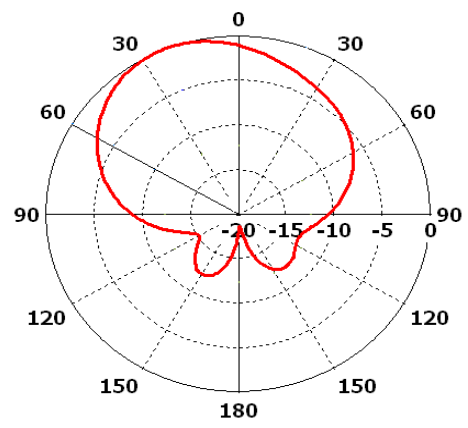

(a) 


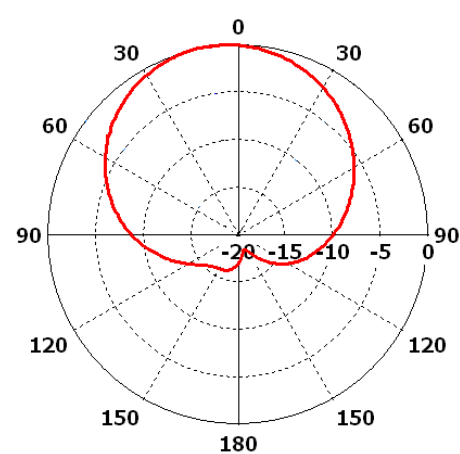

(b)

Fig. 12: Simulated Far-field Radiation Pattern at 2.53 GHz. (a) For $\Phi=$ 0. (b) For $\Phi=90$.

Fig. 12(a) and (b) respectively shows the simulated radiation pattern at $\Phi=0^{\circ}$ and $\Phi=90^{\circ}$ for the proposed two element MIMO system at the resonant frequency $\mathrm{Fr}=2.53 \mathrm{GHz}$. From the polar figure, the designed antenna system produce directional pattern. It is noted that the main beam angle is about broadside angle.

\subsection{Four Element MIMO Array with Polarization Diversity}

In this section $4 \times 4$ MIMO antenna system shown in Fig. 13 is designed. It is supported by LTE-Advanced uplink frequency band employing polarization diversity. Using the same techniques as for the two elements MIMO array, metal structures are placed between antenna elements as well as modifying the ground plane "SGP" for providing greater amount of isolation between microstrip elements. The metal structure width is $4 \mathrm{~mm}$, ground slot width is $4 \mathrm{~mm}$ and the separation between the elements is $9 \mathrm{~mm}$.

In case of MIMO configuration without isolation between antenna elements, the simulated reflection coefficient at all ports of the antennas are blew -10 as shown in Fig.15 (a), and the values of the mutual coupling between elements are blew $17 \mathrm{~dB}$ for the required bandwidth as shown in Fig.16 (a).

The simulation results depicted in Fig. 15 (b) show that the addition of the isolation metal structure and the SGP have very little effect on the bandwidth of the antennas in the array. While the results of the mutual coupling presented in Fig.16 (b) indicate that after introducing the metal-structure between the microstrip antenna elements as well as modifying the ground plane "SGP" as shown in Fig.13 the transmission coefficient is improved from $-17 \mathrm{~dB}$ to $-25 \mathrm{~dB}$.

\section{Port 3}
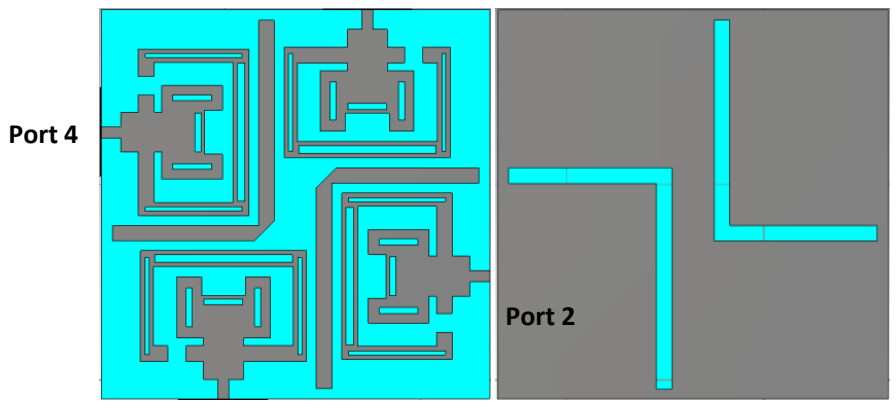

Port 1

Fig.13: Geometry of four orthogonally polarized MIMO antennas, front view and back view.

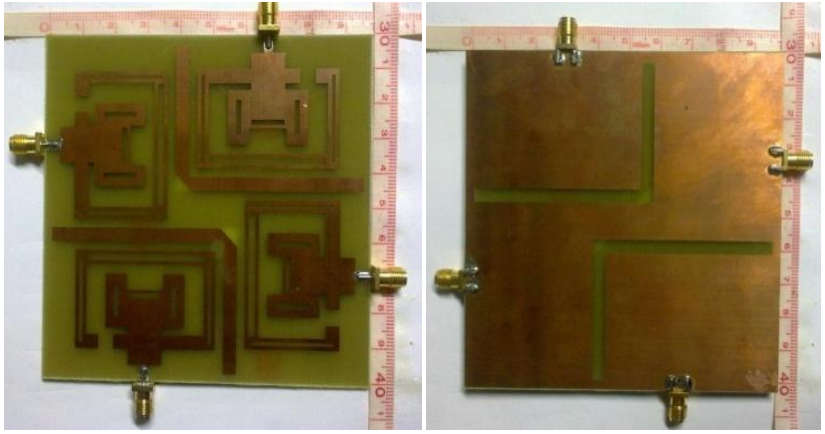

Fig.14: Fabricated Planner MIMO, front view and back view

After designing the four element MIMO array, it is fabricated by photolithographic techniques on Fr4 PCB board and its photograph is shown in Fig. 14. Fig. 15 (c) and Fig. 16(c), respectively, show the Measured Return loss and Mutual coupling for the fabricated array.

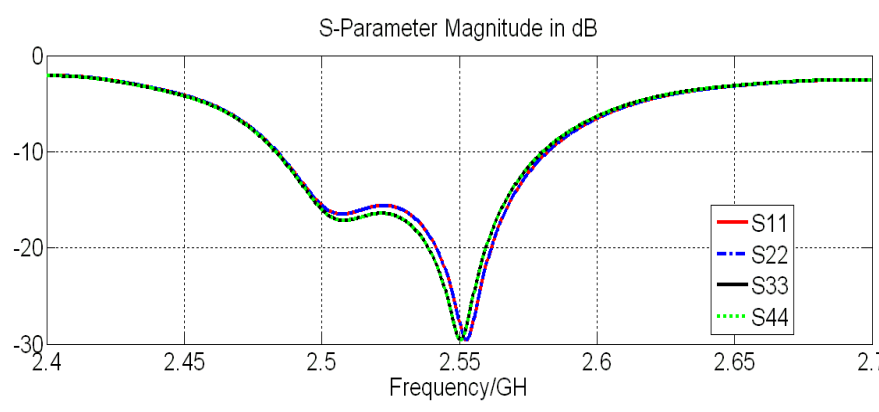

(a)

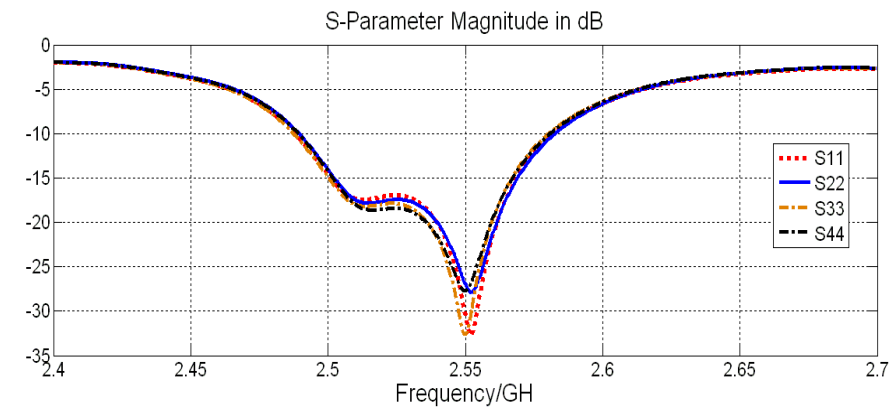

(b)

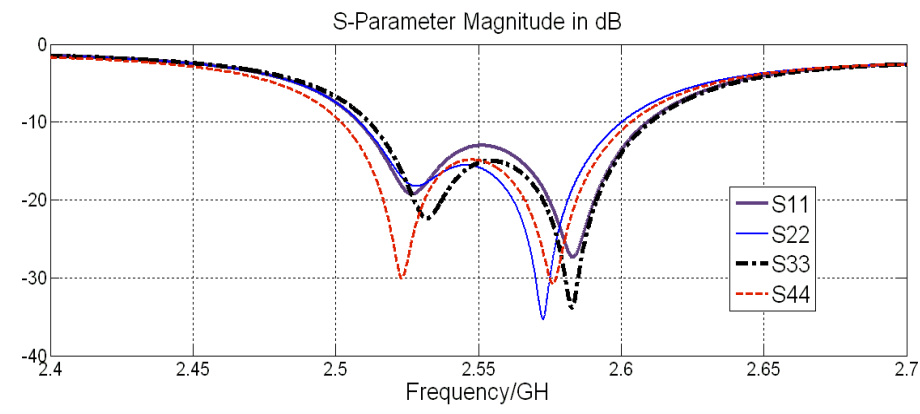

(c)

Fig. 15: Reflection coefficient results of four space polarized antennas with $9 \mathrm{~mm}$ separation

(a) Without isolation between the antenna elements.

(b) With 4 "mm" metal structure between the antenna elements and SGP.

(c) Measured results for the fabricated Planner MIMO 


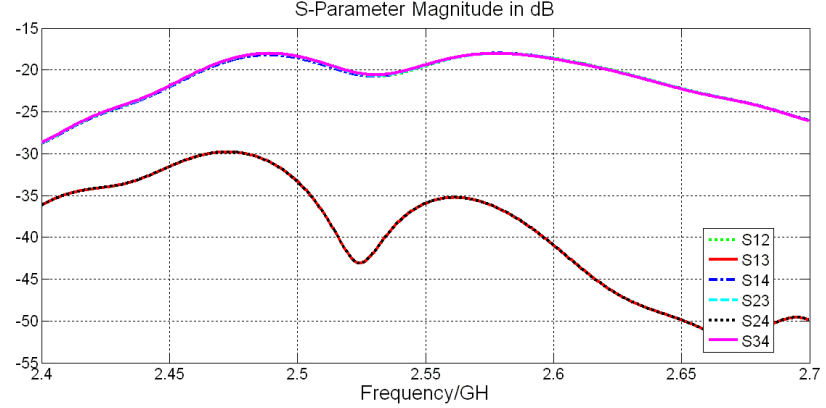

(a)

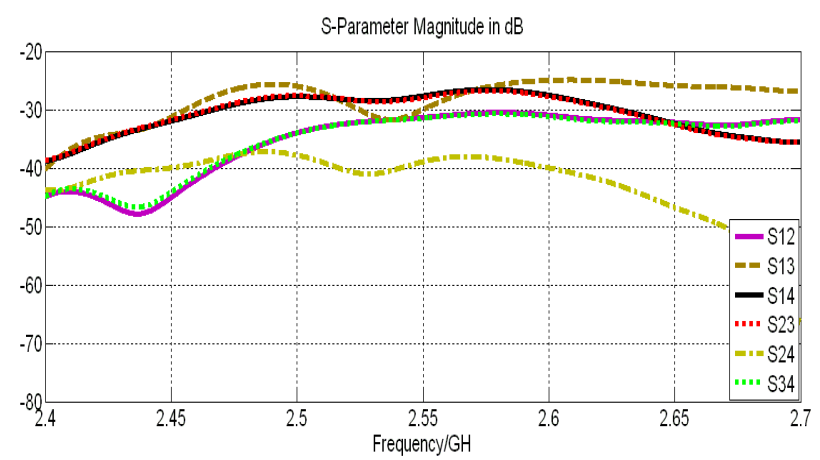

(b)

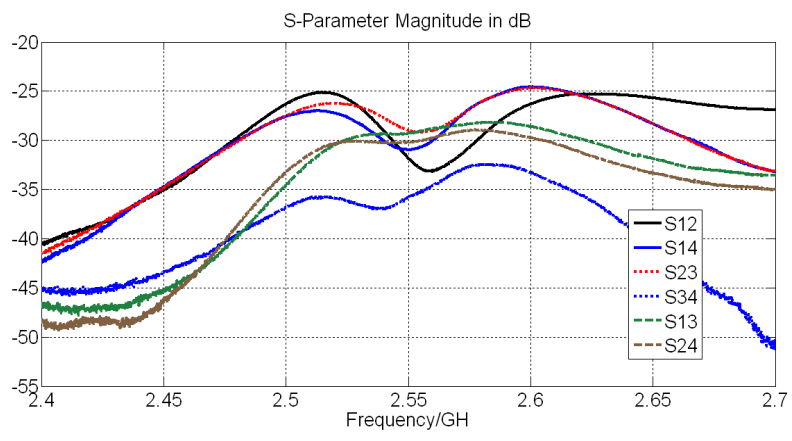

(c)

Fig. 16: Transmission coefficient results of four space polarized antennas with $9 \mathrm{~mm}$ separation

(a) Without isolation between the antenna elements.

(b) With 4 " $\mathrm{mm}$ " metal structure between the antenna elements and SGP.

(c) Measured results for the fabricated Planner MIMO.

By comparing Fig. 15 (b) with Fig. 15 (c) and Fig. 16 (b) with Fig. 16 (c) , it is noticed that there are satisfactory agreement between simulation and measurement results for the proposed MIMO antenna system. But there is about 30 $\mathrm{MHz}$ shift between the measured and simulated data due to the effect of substrate parameter (dielectric constant and thickness), improper soldering of SMA connector or fabrication tolerance.

Fig. 17 (a), and (b) respectively shows the simulated radiation pattern at $\Phi=0^{\circ}$ and $\Phi=90^{\circ}$ for the proposed four element MIMO system at the resonant frequency $\mathrm{Fr}=2.53 \mathrm{GHz}$. From the polar plot, the designed antenna system produces directional pattern. It is noticed that the main beam angle is about broadside angle.

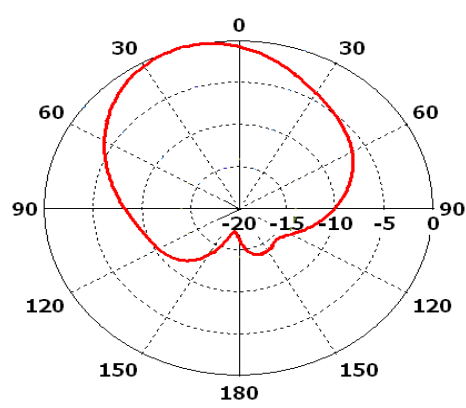

(a)

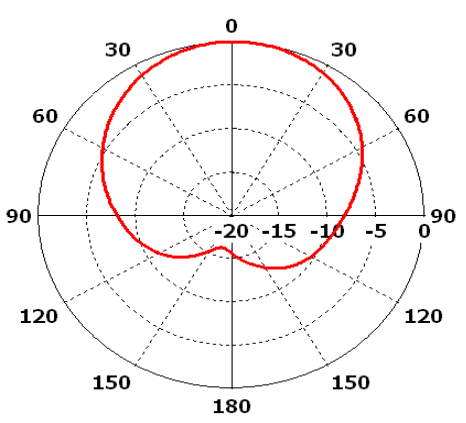

(b)

Fig. 17: Simulated Far-field Radiation Pattern at 2.53 GHz. (a) For $\Phi=0$. (b) For $\Phi=90$.

The correlation coefficient $(\rho)$ :

The correlation between antenna signals (i.e. a measure of relationship between antenna signals) is an essential factor to quantify the efficiency of MIMO systems and it is required to be minimized to achieve the goal of increasing performance.

The correlation coefficient $(\rho)$ between two ports can be calculated from S-parameters as given by the formula [20]:

$$
\rho=\frac{\left|S^{*}{ }_{11} S_{12}+S^{*}{ }_{21} S_{22}\right|^{2}}{\left(1-\left|S_{11}\right|^{2}-\left|S_{21}\right|^{2}\right)\left(1-\left|S_{22}\right|^{2}-\left|S_{12}\right|^{2}\right)}
$$

For good and acceptable isolation, the correlation coefficient should be less than $0.1,[22]$.

CST simulation for the proposed four element planar MIMO system provides a very low correlation coefficient less than 0.02 in the overall the frequency bandwidth from $2.5 \mathrm{GHz}$ up to $2.57 \mathrm{GHz}$ as shown in Fig.18. This is because of the good isolation and low mutual coupling between antennas. The correlation coefficient was calculated for ports (1and 2), ports (1and 3), ports (1 and 4), Ports (2 and 3), Ports (2 and 4) and Ports (3 and 4).

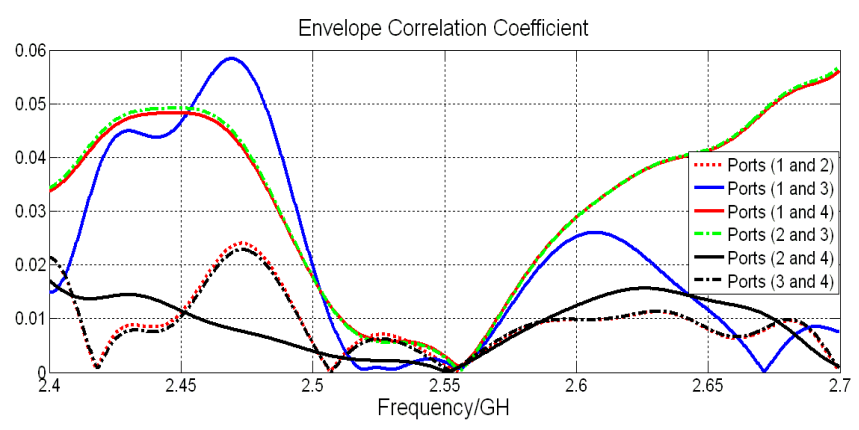

Fig.18: Envelope Correlation Coefficient versus Frequency Plot. 


\section{CONCLUSION}

This paper aimed at the design of a wideband microstrip patch antenna for LTE-A using etched slots at the antenna patch for bandwidth enhancement to overcome the problem occurred in classical microstrip patch antenna that suffers from very fnarrow bandwidth. The designed antenna has been fabricated by using thin film and photolithographic techniques and measured using the Vector Network Analyzer, The simulated and measured results were found to have good match with each other. Then using the designed single element antenna, a four-element MIMO antenna system has been built by employing orthogonal polarization diversity. Isolation between the microstrip elements is increased by placing metal structure between antenna elements. For more isolation between antenna elements, Slotted Ground Plane SGP is utilized. It is found, by using commercial software CST Microwave Studio and measurement that the designed planar MIMO antenna system has sufficiently high return loss and mutual coupling at the required bandwidth of $70 \mathrm{MHz}$. It is found also that the developed antenna system meets the requirements for LTE-Advanced $(2500-2570 \mathrm{MHz})$ band "CA-B7" as of today's standard based on 36.101 Table 5.5-1 (March 2012) [1]. The good return loss < -10dB, Mutual Coupling < $-20 \mathrm{~dB}$ and required bandwidth $>70 \mathrm{MHz}$ are achieved. The antenna has been matched nearly to $50 \Omega$ impedance in the frequency range covering LTE-Advanced band. This work can be extended to build larger arrays.

\section{REFERENCES}

[1] ETSI TS 136101 V10.6.0 (March 2012)

[2] Constantine A. Balanis "ANTENNA THEORY ANALYSIS AND DESIGN" THIRD EDITION.

[3] J.W. Howell, "Microstrip Antennas," IEEE Trans. Antennas Propagat., Vol. AP-23, No.pp.90-93, January 1975

[4] Kai-Fong Lee,Kin-fai Tong “ Microstrip patch antennasbasic characteristics and some recent advances" IEEE 2012 .

[5] R. Garg, P. Bhartia, I. J. Bahl, A. Ittipiboon, "Microstrip Antenna Design Handbook", Artech House, Boston, Mass, USA, 2001

[6] K.L. Wong,"Compact and Broadband Microstrip Antennas" , JohnWiley \& Sons, New York, NY, USA, 2002.

[7] S. M. Duffy, "An enhanced bandwidth design technique for electromagnetically coupled microstrip antennas", IEEE Transactions on Antennas and Propagation, vol. 48, no. 2, pp. 161-164, 2000.

[8] R. Q. Lee, K. F. Lee, K. F. Lee, and J. Bobinchak, "characteristics of a two-layer electromagnetically coupled rectangular patch antenna," Electro. Lett., vol. 23, no. 20, pp. 1070-1072. 1987.

[9] W. Chen, K. F. Lee, and R. Q. Lee, "Spectral -domain moment method analysis of coplanar Microstrip parasitic subarrays" Microw. Opt. Technol. Lett., vol. 6, no. 3, pp. 157-163, 1993.

[10] Rakesh Kumar Tripathi, "Dual Frequency Wideband Rectangular Microstrip Patch Antenna for Wireless Communication System," Electronics and Communication Engineering Department, Thapar University, June 2011.
[11] M. K. B. Amin "Design of Dual Rectangular Ring Antenna with DGS Technique for Wireless and ISM Application” Wireless Application in Biomedical 2012.

[12] M.A.Matin ,M.A.Mohd Ali ,“ Design of broadband stacked E- shaped patch antenna "IEEE 2008.

[13] Jia-Yi Sze, Member, IEEE, and Kin-Lu Wong, Senior Member, IEEE “Slotted Rectangular Microstrip Antenna for Bandwidth Enhancement” IEEE 2000

[14] A. Mukherjee and Hyuck M. Kwon. "Compact Multiuser Wideband MIMO System Using Multiple-Mode Microstrip Antennas" Proceedings of Vehicular Technology Conference Spring 2007 pp584-588 Apr 2007

[15] N. Tiwari, D.N. Nagwanshi, and S. Dwivedi "Design of U-Shape microstrip patch antenna for Bluetooth application at $2.4 \mathrm{GHz}$ " International Journal of Innovation and Scientific Research ISSN 2351-8014 Vol. 6 No. 1 Aug. 2014

[16] M.T Ali, N.Nordin, Norsuzila Ya'acob and M.N.Md Tan "Design of Wideband Microstrip Patch Antenna Using L-Probe Fed at $2.6 \mathrm{GHz}$ " International Conference on Computer and Communication Engineering (ICCCE 2012), 3-5 July 2012, Kuala Lumpur, Malaysia

[17] Harshal Nigam, Mithilesh Kumar "Design and Analysis of 2X2 MIMO System for $2.4 \mathrm{GHz}$ ISM Band Applications" International Journal of Advanced Research in Computer Engineering \& Technology (IJARCET) Volume 3, Issue 5, May 2014.

[18] Matilde Sanchez-Fernandez, Eva Rajo-Iglesias, Oscar Quevedo-Teruel,M. Luz Pablo-Gonzalez. "Spectral Efficiency in MIMO Systems Using Space and Pattern Diversities Under Compactness Constraints" IEEE T1637-1645,May 2008.

[19] Arny Adila Salwa Ali1, Sharlene Thiagarajah, "A Review on MIMO Antennas Employing Diversity Techniques" Proceedings of the International Conference on Electrical Engineering and InformaticsInstitut Teknologi Bandung, Indonesia June 2007 pp no.17-19

[20] K. Jagadeesh Babu, Dr.K.Sri Rama Krishna, Dr.L.Pratap Reddy, "A Multi Slot Patch Antenna for 4G MIMO Communications" International Journal of Future Generation Communication and Networking Vol. 4, No. 2, June, 2011.

[21] O.F. Ahmed, R.S. Ghoname, A. A. Zekry, "Mutual Coupling Reduction of MIMO Antennas using Parasitic Elements for Wireless Communications" International Journal of Computer Applications, Volume 62- No.19, January 2013.

[22] Harshal Nigam , Mithilesh Kumar , "A Compact MIMO Antenna Design for $2.4 \mathrm{GHz}$ ISM Band Frequency Applications" International Journal of Electronics and Computer Science Engineering 2014.

[23] Md. Ashikur Rahman, Moinul Hossain, Ibnul Sanjid Iqbal "Design and Performance Analysis of A Dualband Microstrip Patch Antenna for Mobile WiMAX, WLAN, Wi-Fi and Bluetooth Applications" 3rd international conference on Informatics, Electronics \& Vision 2014. 